SISTEMA
ELETRÔNICO
DE REVISTAS
SER I UfPR

\title{
Ecoethos da Amazônia: interação e ludicidade juvenil mediada por um jogo de simulação
}

\section{Ecoethos da Amazônia: interaction and youth playfulness in a simulation game}

\author{
Iris Rianne Santana ALVES ${ }^{1 *}$, Maria Inês Gasparetto HIGUCHI² \\ ${ }^{1}$ Instituto Chico Mendes de Conservação da Biodiversidade (ICMBio), Manaus, AM, Brasil. \\ ${ }^{2}$ Instituto Nacional de Pesquisas da Amazônia (INPA), Manaus, AM, Brasil. \\ *E-mail de contato: irisrianne@gmail.com
}

Artigo recebido em 11 de setembro de 2017, versão final aceita em 27 de março de 2019.

RESUMO: O jogo de simulação Ecoethos da Amazônia utiliza da simbologia de cinco elementos (Terra, Água, Ar, Fogo e Cuidado), para simular a realidade ambiental amazônica no uso de maquetes. Nas estações, os participantes devem encontrar soluções para os dilemas apresentados: na estação Água sobre a poluição, desperdício e abastecimento; na estação Ar, a emissão de gases de efeito estufa, sequestro de carbono e uso da terra; naestação Terra, a biodiversidade, relevo e recursos hídricos; e na estaçãoFogo, as alternativas energéticas observando o ambiente, biodiversidade e aspectos socioeconômicos. O cuidado é transversal a todas elas a partir da ação dos participantes. O objetivo desse estudo foi avaliar a experiência vivenciada e o entendimento sobre os conteúdos abordados estruturados no método de avaliação da Experiência do Usuário em jogos e na Taxonomia Bloom. Após a participação no jogo aplicou-se um questionário com 168 alunos do $6^{\circ}$ ao $9^{\circ}$ ano do ensino fundamental. Essa vivência foi analisada de acordo com categorias predefinidas: definição da experiência vivida, estética do jogo, dificuldades sentidas na manipulação, sensações vivenciadas, entendimento da representatividade das peças, agradabilidade e capacidade do jogo depromover mudanças no comportamento. Comos resultados, ficou evidente que o Ecoethos da Amazônia se trata de um jogo que ensina, diverte e possibilita a interação responsável. O jogo desperta a atenção e é desafiador e a manipulação das peças e os dilemas foram compreensíveis apesar dos desafios. A imersão impulsionou uma singela responsabilidade ambiental, além de apontar a potencialidade do jogo para sensibilizar, informar e refletir sobre aspectos socioambientais.

Palavras-chave: Amazônia; jogo de simulação; educação ambiental; juventude e meio ambiente.

ABSTRACT: Ecoethos da Amazonia is a simulation game that explores the symbology of the five elements (Earth, Water, Air, Fire, and Care) by the use of tridimensional models. The set consisted of a circular space with four stations, 
each representing one of the four natural elements. The players must solvethe challengespresented to them in each station. The Water pollution station deals with waste and water supply; the Air station brings questions about greenhouse gas emission, carbon sequestration, and land use; the Earth station presents questions focused on biodiversity, relief, and water resources; the Fire station alternative energy options are explored, always considering the biodiversity, the physical-geographical, the social and the economic characterization of the environment. The aim of this study was to evaluate players' experience and understanding of the concepts explored during the activity. The theoretical approach was based on the Gamer User Experience Evaluation and the Bloom Taxonomy. Participated in this study 168 students ( $6^{\circ}$ to $9^{\circ}$ grades) of public schools. Some pre-established categories were considered for the analysis: opinion about the experience, game layout, difficulties handling parts, feelings triggered, understanding the representation of the parts, playfulness, and potential in changing behavior. Ecoethos da Amazônia was considered a game that teaches, entertains and enables responsible interaction. The game engages the participant's attention and the situations presented were challenging buteasy to understand. The results showed that the game experience can promote environmental responsibility while pointing out the potential of the game to raise awareness, inform and reflect on social and environmental issues.

Keywords: Amazon; simulation game; environmental education; youth and environment.

\section{Introdução}

A dinâmica interativa e lúdica não é um requisito novo nos processos educativos, mas tradicionalmente o "quadro e giz" são adotados de forma exaustiva por diversos motivos. Algumas modalidades educativas tentaram, com sucesso, introduzir metodologias mais participativas e lúdicas. Experiências assim são encontradas em programas de Educação Ambiental (EA), embora essa esteja mais ativamente relacionada à atividade em contextos não escolares (Higuchi et al., 2010; Higuchi et al., 2012). É importante observar, no entanto, que a inserção da EA no contexto escolar tem o objetivo de construir conhecimentos, atitudes e valores a fim de possibilitar a participação desse público na busca de uma sociedade sustentável (Castro, 2002; Corral-Verdugo \& Pinheiro, 2004).

De qualquer forma, o processo educativo deve se valer de metodologias ativas que assegurem o interesse e a efetiva aprendizagem dos alunos. Não é o objetivo desse texto argumentar a importância pedagógica dessas metodologias, mas defender que a inovação e o uso de formas dinâmicas, interativas e lúdicas são um desafio também para a EA. Portanto, segundo Alves \& Hetkowski (2012), entre tantas metodologias, o jogo continua sendo imperativo na produção do prazer em aprender e no sucesso da aprendizagem.

O jogo educacional é uma forma estimulante de tratar de conteúdos abstratos de maneira interativa, como descrevem Balasubramanian \& Wilson (2005, p. 2) ao definir o jogo como "um ambiente interativo de aprendizagem envolvente, que cativa um jogador oferecendo desafios". Segundo Lee \& Hammer (2011), alguns tipos de jogos educacionais estimulam a produtividade e criatividade entre alunos, permitindo a eles experimentar emoções e papéis, além da liberdade de explorar múltiplas competências e habilidades. Entre diferentes tipos de jogos se destaca o formato de simulação da realidade, cujo potencial na facilitação da aprendizagem 
a partir da tomada de decisão, reconhecimento e resolução de problemas é apontado por Balasubramanian \& Wilson (2005). Nesses jogos, o participante faz uso de uma complexidade de habilidades cognitivas, sociais e afetivas.

O termo simulação corresponde aoaparentar ou fazer parecer real. Partindo deste enfoque, Taylor (1991) indica que os jogos de simulação devem apresentar algumas características, tais como: permitir o uso de modelos físicos na representação da realidade; expor os participantes a determinadas características pré-selecionadas, relativamente controladas e livres de riscos; facilitar que os participantes assumam papeis que impliquem em diversos graus de cooperação; proporcionar variadas experiências no ambiente simulado em resposta à qualidade da tomada de decisões. Enfim, o jogo de simulação em EA solicita uma disposição ampla o bastante para incluir discussões sobre os desafios ambientais cada vez mais emergentes.

É evidente que a EA busca estabelecer mudanças comportamentais para formação da responsabilidade e cidadania ambiental. Portanto, aEA deve resultar em estímulos pró-ambientais que visem construir uma nova realidade socioambiental e refletir sobre os atuais valores éticos para a busca de uma responsabilidade ambiental (Jacobi, 2003; Santos, 2012). De modo especial a fim de efetivar essa meta, que é parte integrante de uma EA crítica transformadora (Loureiro, 2004).

Aspectos como cultura, história e economia são importantes para a construção de programas de EA que utilizem temáticas locais e, quando possível, devem ser construídos pelos próprios atores sociais a fim de buscar soluções para a problemática ambiental. Logo, como promover práticas educativas tratando de aspectos locais e globais? Como levar os jovens a questionar sobre problemas ambientais e propor soluções para situações reais e ao mesmo tempo estimulá-los a reivindicar seus direitos e se posicionarem frente a suas responsabilidades como cidadãos?

Esses questionamentos não exigem respostas com modelos prescritivos para solucionar conflitos generalizados, mas sim estimulo à reflexão sobre práticas cotidianas e possíveis mudanças de comportamento por parte dos indivíduos. Essa reflexão é necessária para uma melhoria da relação pessoa-ambiente, sendo que a prática educativa para uma transformação sustentável desta relação não pode se desvencilhar das diferentes realidades e contextos históricos que constituem uma sociedade. A malha contextual é essencial para proporcionar a desejada emancipação dos sujeitos de modo a contemplar suas ações no e com o ambiente. A participação ativa e consciente por meio do conhecimento reflexivo e crítico da realidade biológica, social, política, econômica e cultural possibilita a busca de soluções para problemas ambientais.

A educação ambiental e a psicologia ambiental têm auxiliado para a efetiva mudança do comportamento humano em prol da sustentabilidade. Isso só é possível ao permitir às pessoas colocarem em questão seus valores éticos e comportamentais a partir de uma visão integrada sobre o cuidado com o ambiente.

Apropriando-se desses pressupostos é que o jogo de simulação chamado Ecoethos da Amazônia foi desenvolvido. Os dilemas socioambientais presentes neste jogo possibilitam refletir sobre a difícil missão de consolidação da sustentabilidade em sua dimensão social, econômica, cultural e ambiental.

O jogo é um devir sobre a complexidade das demandas sociais e capacidade de suporte 
ambiental, tendo como tema a realidade do bioma amazônico. Ao fazer parecer real o ambiente amazônicocom o uso de maquetes, o jogo solicita uma concreta tomada de atitude diante dos problemas apresentados.

Este jogo foi criado para tratar das metas da EA descritos na Recomendação da Conferência Intergovernamental sobre Educação Ambiental aos Países Membros ocorrida em UNESCO (1978). Também foi destacado por Smyth (1995) e Sato (2002) como etapaspara se alcançar a cidadania ambiental: sensibilização ambiental; compreensão ambiental; competência ambiental e responsabilidade com compromisso ambiental. Segundo Higuchi et al. (2014), para atingir a cidadania ambiental são necessários todos esses atributos educativos, ou seja, tanto a sensibilização quanto a informação, a competência e a responsabilidade devem ser largamente estimuladas para que se avance nos propósitos educativos.

Jacobi (2004) aponta que formando cidadãos com a capacidade de desenvolver um pensar global e agir local, a EA possibilita maior reflexão sobre a co-responsabilidade e visão crítica sobre as questões socioambientais. Narrativas importantes como essas muitas vezes deparam em práxis para atingir tal ideal. Como favorecer tamanha complexidade em abordagens metodológicas que atendam demandas outras do público envolvido? Vemos com certo alívio que a sensibilização, a informação e competências têm ganhado força e contribuido com mudanças. No entanto, é penoso verificar que aspectos de responsabilidade e compromisso têm muito que avançar.

Partindo da necessidade de abordagens metodológicas inovadoras, o jogo criado estaria aten${ }^{1}$ http://ecoethos.weebly.com/ dendo a seus objetivos? Apresentamos nesse texto parte da investigação que procurou compreender a experiência vivenciada pelos participantes do jogo e o entendimento sobre os conteúdos abordados, estruturados no método de avaliação da Experiência do Usuário em jogos e na Taxonomia Bloom.

\subsection{Sobre o jogo de simulação Ecoethos da Amazônia}

O Ecoethos da Amazônia ${ }^{1}$ usa a tridimensionalidade como base para a simulação de diferentes espaços com a finalidade de representar áreas geofísicas naturais e construídas no formato de maquetes, caracterizando formas de uso e apropriação. Esta técnica denominada tridimensionalidade de modelagem topográfica ou topológica é destacada por autores como Aragonés \& Amérigo (2002) e Higuchi \& Kuhnen (2008) como importante ferramenta de investigação para pesquisa voltada à análise da conduta ambiental.

Desde 2006, o Laboratório de Psicologia e Educação Ambiental (LAPSEA) do Instituto Nacional de Pesquisas da Amazônia (INPA) discute em suas propostas pedagógicas bases teóricas que hoje fundamentam a plataforma educacional denominada Ecoethos da Amazônia. Este jogo é constituído por quatro estações que possuem uma maquete base com blocos removíveis onde estão representadas as situações problemas para cada um dos elementos naturais (água, ar, fogo e terra). Nas estações, os participantes devem encontrar soluções para os dilemas apresentados: na estação Água, dilemas sobre a poluição, desperdício e abastecimento; na estação $\mathrm{Ar}$, dilemas sobre a emissão de gases de efeito estu- 
fa, sequestro de carbono e uso da terra; na estação Terra, dilemas sobre a biodiversidade, relevo e recursos hídricos; e na estação fogo, dilemas sobre as alternativas energéticas observando o ambiente, biodiversidade e aspectos socioeconômicos.

Os blocos removíveis podem ser substituídos por outros blocos que representam as possíveis soluções para a problemática identificada pelos participantes. No ensaio lúdico há o quinto elemento que é representado pela ética dos participantesatravés das decisões e substituições de peças da maquete, atendendo sempreàs demandas ambientais e sociais.

$\mathrm{O}$ jogo é realizado em forma de circuito com cenário teatral onde os participantes são conduzidos pelo Mestre Ecoethos - personagem responsável por promover a imersão dos participantes no ambiente simulado. Em seguida, são divididos em quatro (4) equipes e distribuídos em cada uma das estações e então são recebidos pelos respectivos Mestres Água, Ar, Fogo e Terra. Esses, por sua vez, instruem sobre as tarefas que os participantes devem solucionar em um tempo estimado de 15 minutos.

Ao final de cada missão em cada estação são pontuados valores que correspondem às mudanças efetuadas. Isso se repete quatro vezes em forma de circuito, ou seja, os participantes seguem para a estação seguinte a fim de que todos vivam a experiência em todas as estações. Ao final das quatro tarefas o valor resultante compõe o Índice de Sustentabilidade (IS) alcançado, ou seja, o grau ético dos participantes, definindo o quanto eles atenderam as demandas sociais com equilíbrio ambiental.

Portanto, o maior desafio do processo educativo na atualidade está voltado especialmente para a construção de responsabilidades ambientais como descrevem Smyth (1995), Sato (2002) e Higuchi \& Azevedo (2004) ao apontar a necessidade de uma maior reflexão e protagonismo ambiental, como a responsabilidade e cidadania ambiental, para efetivação das metas propostas pela EA. O jogo de simulação tenta atender tais necessidades por meio de metodologia interativa e lúdica que a "gameficação" permite. Para se verificar a eficácia e eficiência dessa abordagem, esse estudo se ocupou de investigar como alunos do ensino básico avaliaram esse processo.

\section{Metodologia}

Esta investigação se caracteriza como um estudo qualitativo de abordagem descritiva e exploratória (Gunther et al., 2008) com aplicação de questionários a alunos do $6^{\circ}$ ano ao $9^{\circ}$ ano do ensino fundamental. As categorias de análise contidas no formulário foram incluídas a partir de uma adaptação dos elementos propostos pela Taxonomia Bloom (TB) e Experiência do Usuário (EU).

\subsection{Taxonomia Bloom e Experiência do Usuário}

A palavra taxonomia é muita usada pela área biológica e refere-se à classificação dos seres vivos. Entretanto, nesse estudo não possuio mesmo significado, poissegundo Bloom et al. (1988), trata-se de organizar e classificar os objetivos do sistema educacional, facilitando a troca de informações entre pesquisadores e a própria organização curricular e de avaliação. A TB está estruturada em três domínios, são eles: o cognitivo, o afetivo e o psicomotor.

Nesse contexto, instrumentos de planejamento e avaliação didático-pedagógicos como a TB são utilizados com o intuito de identificar o 
desenvolvimento cognitivo, englobando a aquisição conhecimentos e atitudes mediante o processo ensino-aprendizagem. Portanto, nesse estudo objetivou-se analisar o entendimento dos participantes sobre a temática socioambiental.

A Experiência do Usuário (EU) por sua vez visa analisar as percepções do sujeito resultantes da interação com o objeto, sendo utilizado principalmente para avaliar a satisfação de produtos (Tullis \& Albert, 2013).Dessa forma, a avaliação sobre determinado fenômeno ou objeto, aqui em particular a interação com o jogo Ecoethosda Amazônia, é medida através da experiência proporcionada mediante a participação no jogo. Tal experiência pode ser observada ou mensurada por meio da interação da pessoa com o que é observado.

Esta metodologia ganhou espaço no âmbito educacional quando Bernhaupt (2010) e Savi et al., (2010) apresentou estecomo um novo direcionamento para avaliar um jogo educativo. Atendo-se aos elementos que fundamentam esse método, são eles: imersão, interação social, desafios, divertimento/lazer e competência.

Estas fundamentações teóricas (TB e EU) serviram de base para elaboração dos instrumentos de coleta de dados e posterior análise dos dados.

\section{Resultados e discussões}

A aplicação do questionário foi realizada com alunos do $6^{\circ}$ ao $9^{\circ}$ anos de escolas da rede pública de Manaus-AM, em suas respectivas escolas, atendendo a um prazo máximo de quinze dias após a participação no jogo. Participaram 168 alunos $(\mathrm{M}=80 ; \mathrm{F}=88)$, com idade entre 10 e 17 anos de idade, sendo que $29 \%$ deles tinha 12 anos, $20 \%$ tinha
14 anos, 20\%tinha 11 anos, $15 \%$ tinha13 anos, $12 \%$ tinha 15 anos, $2 \%$ tinha 16 anos, $1 \%$ tinha 10 anos e $1 \%$ tinha 17 anos. Entre os alunos, $45 \%$ cursavam o $6^{\circ}$. ano; $15 \%$ o $7^{\circ}$. ano; $14 \%$ o $8^{\circ}$. ano e $26 \%$ o $9^{\circ}$. ano (Tabela 1).

TABELA1- Distribuição dos participantes em função do ano escolar e gênero.

\begin{tabular}{ccccc}
\hline $\begin{array}{c}\text { ANO } \\
\text { ESCOLAR }\end{array}$ & FEM & MASC & TOTAL & TOTAL \% \\
\hline $\mathbf{6}^{\mathbf{0}}$ & 40 & 37 & 77 & $\mathbf{4 5}$ \\
$\mathbf{7}^{\mathbf{0}}$ & 13 & 12 & 25 & $\mathbf{1 5}$ \\
$\mathbf{8}^{\mathbf{0}}$ & 12 & 11 & 23 & $\mathbf{1 4}$ \\
$\mathbf{9}^{\mathbf{0}}$ & 22 & 21 & 43 & $\mathbf{2 6}$ \\
TOTAL & 88 & 80 & 168 & - \\
TOTAL \% & $\mathbf{5 2 \%}$ & $\mathbf{4 8 \%}$ & $\mathbf{1 0 0 \%}$ & - \\
\hline
\end{tabular}

De modo geral, os alunos se encontravam em escolaridade esperada para a idade (96\%), exceto uma pequena parcela (4\%) dos participantes que estava fora da faixa etária prevista.

\subsection{Experiência educativa no Ecoethos da Amazônia}

A EUno Ecoethos da Amazônia foi analisada de acordo com sete categorias predefinidas para avaliação da experiência vivenciada em jogos, expressando como os participantes avaliaram os atributos referentes à: a) definição da experiência vivida; b) estética do jogo; c) dificuldades sentidas na manipulação; d) sensações vivenciadas durante o jogo; d) entendimento da representatividade das peças; e) aspectos de agradabilidade; e f) capacidade do jogo em promover mudanças no comportamento. 


\subsection{Definição da experiência vivida}

A participação dos alunos durante o jogo proporcionou diversas sensações a partir de diferentes olhares sobre o Ecoethos da Amazônia. Entre as alternativas apresentadas, $86 \%$ dos participantes consideraram tratar-se de um jogo que ensina, para $9 \%$ seria uma aula divertida, para $4 \%$ seria apenas um jogo e para $1 \%$ seria um passatempo. Ao associarem o Ecoethos da Amazônia como um jogo que ensina, confirma-se os objetivos designados ao jogo pelo grupo proponente (Higuchi et al., 2010; Higuchi, 2013; Azevedo, 2014).

O jogo adota conteúdo curricular relacionado às mudanças climáticas, uso social da água, fontes energéticas e uso adequado da Terra. Portanto, tal resultado possibilita associar os termos "jogo" e "ensino", isto corrobora com o que Mattos \& Fagundes (2010) apontam: que o lúdico possibilita a aprendizagem de forma divertida e prazerosa.

Os resultados mostram, portanto, que os alunos conseguiram apreender o potencial deste jogo para discutir conteúdos curriculares e sua contribuição em abordar tais temas de maneira mais didática, a fim de promover o interesse dos participantes e aprendizagem sobre conteúdos tão abstratos referentes aos quatro elementos naturais e a inserção da responsabilidade sobre eles.

\subsection{Estética do jogo}

O jogo foi elaborado visando promover um envolvimento em todos os sentidos no jogo (imersão) por parte dos participantes. Para essa imersão, a estética foi planejada considerandoo cenário visual (arranjo espacial, mestres com vestes alusivas ao elemento, estações com maquetes diferenciadas) e auditivo (trilha sonora específica desde a recepção até a despedida e enunciados categóricos), as quaisbuscavam aproximar os participantes da realidade do bioma amazônico de modo aserem atraídos por ele.

Entre as alternativas apresentadas, o cenário físico como um todo foi apontado como predileção estética por $50 \%$ dos participantes, seguindo-se pela atratividade especial provocada pelas maquetes que foram apontadas por $36 \%$ dos participantes. Já a estética das vestimentas dos mestres e a música foram apontadas por $5 \%$ e $2 \%$ respectivamente. Apenas $1 \%$ dos participantes disse não ter gostado da estética do jogo e $7 \%$ indicaram outros aspectos salientes da estética como, por exemplo: "O que eles ensinam sobre o nosso planeta"; "O clima junto com a música"; "A experiência de aprender algo novo e que vai ajudar o nosso planeta terra"; "Na verdade eu achei tudo legal".

Os resultados apontados sugerem que a estética colorida e a inovação das miniaturas foram pontos de excelência no jogo, de tal forma que os demais aspectos (música e vestimentas) foram secundários, porém integrantes para a sensação de agradabilidade e beleza proporcionado pelo jogo.

Este resultado evidencia que a estética é primordial para apreensão da atenção dos participantes, possibilitando a imersão no jogo, aspecto importante nos jogos de simulação (Savi et al., 2010). Portanto, uma avaliação estética em um jogo não deve estar centrada apenas no visual, mas na experiência do jogador interagindo com o jogo (Petry et al., 2013), conformefoi observado quanto ao grau de imersão que tais aspectos possibilitaram aos participantes. 


\subsection{Dificuldades sentidas na manipulação}

A manipulação das peças nojogo de simulação é um requisito básico, considerando a idade para o qual foi criado. Nesse caso, o tamanho das maquetes, a altura, o tamanho e o peso dos blocos e as miniaturas contidas neles devem permitir um fácil manuseio para retirar e inserir novos blocos. Considerando que os blocos tinham em média o tamanho de $20 \mathrm{~cm}$ a $30 \mathrm{~cm}$, e pesavam em torno de $400 \mathrm{~g} \mathrm{com}$ uma das faces com as miniaturas correspondentes (árvores, casas, animais e demais aparatos já descritos), teria os adolescentes alguma dificuldade de retirar da base e recolocar os removíveis?

Observou-se que, apesar de algumas diferenças no material utilizado em cada estação, $81 \%$ dos participantes apontaram não ter tido dificuldade em manipular as peças, enquanto que $18 \%$ indicaram ter sentido alguma dificuldade de manuseio e apenas $1 \%$ dos participantes indicou outras dificuldades. Entre os participantes que manifestaram ter tido dificuldade, estas se referiam mais àcompreensão da tarefa a ser cumprida e acomo lidar com as trocas dos blocos ou como fazer em conjunto com os demais colegas do grupo do que à peça física em si. Para esses participantes, as justificativas apontam para um aspecto cognitivo (falta de entendimento do conteúdo) de como utilizar os blocos e não paraa concretude delas. Portanto, corroboram com a adequação da ergometria dos blocos.

Constata-se assim, que as maquetes e os blocos substituíveis foram presumidamente de fácil manipulação motora para o uso nas tarefas solicitadas. Portanto, dois fatores estão relacionados à manipulação, são eles: estética e motricidade. O primeiro diz respeito ao tamanho, cores e representatividade da realidade das maquetes, os quais contribuíram para superação dos desafios propostos (Petryet al., 2013). Já a motricidade trata da habilidade em movimentar as peças, o que contribuiu para a baixa dificuldade e positivo desempenho no jogo. Tais fatores, de acordo com Schwartz (2014), são coadjuvantes na prática da interação, uma vez que as pessoas não assimilam apenas observando, mas interagindo de forma concreta.

\subsection{Sensações vivenciadas durante o jogo}

O Ecoethos da Amazônia enquanto jogo com premissas propostas pela EU (Savi et al., 2010; Bernhaupt, 2010; Tullis \& Albert, 2013) foi criado para promover envolvimento, interação, eficácia, motivação, capacitação, interesse e responsabilidade. As alternativas apresentadas aos participantes sugeriam as seguintes sensações: a) envolvimento (não percebi o tempo passar); cooperação (gostei de meu amigo ter ajudado); falta de interesse (queria acabar logo); motivação (desafiado a cumprir as tarefas); apropriação (mais responsável); capacitação (com habilidade para superar desafios).

Os resultados apresentados pelos participantes sobre as sensações vivenciadas no jogo foram bastante diferenciados. Entre os participantes, 26\% manifestaram se sentir capacitados, isto é, habilitados para superar desafios; $23 \%$ deles se sentiram motivados com os desafios colocados; $17 \%$ indicaram a sensação de se sentir mais responsável; $17 \%$ sentiram o prazer da interação por meio da ajuda dos colegas na resolução dos desafios; e 15\% sentiram-se inteiramente envolvidos a ponto de não perceber o tempo passar. Apenas 2\% expressaram uma sensação de desagradabilidade querendo aca- 
bar logo o jogo. Tais nuances são benéficas, como apontam Petry et al. (2013), ao afirmarem que o fluxo no jogo de sentimentos positivos e negativos como momentos divertidos ou situações frustrantes promovidas pelo baixo desempenho nos desafios propostos, estimula maior interesse dos jogadores no jogo.

A partir desses resultados, observa-se que entre a maioria dos participantes as sensações relativas à competência e motivação foram as que obtiveram maior índice de respostas. É evidente também que a responsabilidade, cooperação e envolvimento foram notificados pelos participantes. Tais sensações conferemao jogo Ecoethos da Amazônia características notáveis para ser utilizado como recurso de EA.

\subsection{Representatividade das peças- miniaturas}

Um aspecto importante em jogos de simulação é a permissão do uso de modelos físicos na representação da realidade. Portanto, as peças do jogo (maquete e blocos avulsos substituíveis) foram confeccionadas para serem rapidamente reconhecidas como situações do mundo real.Por exemplo: tipos de fontes energéticas; situações de desperdício de água; relevo e cobertura florestais amazônicas; plantios agrícolas; sistemas agroecológicos; arranjo de urbanização, entre outros. Se tais miniaturas não tiverem essa representatividade reconhecida, o desempenho pode ser comprometido.

Para a maioria dos participantes $(67 \%)$, as peças foram fáceis de identificar, isto é, mostraram com adequação a realidade que se propunham representar. Já para $29 \%$ dos participantes, estas não estavam adequadas e $4 \%$ apontaram que algumas delas precisavam ser melhoradas.
Observa-se que em determinadas situações a representatividade requer uma complexa elaboração artística e arquitetônica, que nem sempre se alcança concretamente. Nesse sentido, há que se considerar a capacidade de projetar na miniatura o real, e, portanto, isso requer uma estrutura cognitiva que permita tal entendimento. Ainda assim, constata-se que o distanciamento sobre a realidade e a abordagem dada aos conteúdos curriculares apresentam-se mais complexos para participantes das series iniciais, que devido ao uso desses materiais receberam um estímulo para o entendimento dessa realidade complexa presente no Ecoethos da Amazônia.

Segundo Rodrigues \& Nunes (2010), brincar é estabelecer interação com algo ou alguém e, portanto, essa consciência sobre o real e a responsabilidade da situação representada no jogo se constrói a partir deste contato com o objeto (blocos substituíveis e maquetes base) e interação entre os participantes.

\subsection{Aspectos de Agradabilidade}

Para compreensão sobre a experiência vivenciada no Ecoethos da Amazônia, alguns fatores são imprescindíveis como o envolvimento dos participantes para tomar decisões em equipe, desafios estimulantes apresentados pelos mestres, a curiosidade do participante de explorar novos temas em cada estação e a aplicabilidade do que viu no jogo em seu cotidiano.

A agradabilidade da experiência proporcionada pelo jogo foi evidenciada por $51 \%$ dos participantes que indicaram gostar de tomar decisões em equipe, $25 \%$ indicaram ter gostado das tarefas dadas pelos mestres, enquanto que $12 \%$ indicaram gostar de aplicar o que viu no jogo, outros $11 \%$ indicaram 
gostar de mudar de estações (dinamismo) e apenas $1 \%$ não gostou do jogo.

Tais resultados evidenciam que a interação e cooperação foram os aspectos que mais agradaram os participantes durante o jogo, mostrando assim que o jogo que investe no trabalho em equipe agrada os adolescentes. Portanto, é imprescindível a discussão sobre tais aspectos, como apontam Silva et al. (2012), segundo os quaisem qualquer fase da vida é importante a abordagem da socialização, cooperação, permitindo despertar no indivíduo a coletividade.

Os desafios apresentados no jogo pelos Mestres foram também aspectos que agradaram aos participantes. Esses procedimentos próprios do jogo se mostraram como principais para que os adolescentes demonstrassem satisfação em vivenciar as sessões do Ecoethos da Amazônia.

A possibilidade de poder aplicar conhecimentos em seu cotidiano junto com a dinamicidade e movimentação que o jogo exigia foi também notada no aspecto de agradabilidade, embora não tão acentuada como os demais aspectos. Esses resultados corroboram com estudos que apontam recursos direcionados a manter curiosidade e interesse dos participantes devem não apenas ter um conteúdo apropriado cognitivamente, mas também se preocupar com a forma como tal recurso é apresentado (Higuchi et al., 2010).

\subsection{Capacidade do jogo depromover mudanças no comportamento}

As metas da EA tais como a sensibilização ambiental, compreensão ambiental, competência ambiental, responsabilidade ambiental para a ci- dadania ambiental (Higuchi \& Azevedo, 2004) são pressupostos que o Ecoethos da Amazônia busca alcançar. Destaca-se, por exemplo, a promoção de mudanças do comportamento dos sujeitos mediante reflexão de atitudes sobre as demandas sociais apresentadas no jogo, estimulando sobretudo a responsabilidade e cuidado ambiental (Higuchi, 2013; Azevedo, 2014; Azevedo \& Higuchi, 2015).

Constatou-se que os participantes expressaram a capacidade que o jogo tem depromover mudanças no comportamento, sendo que $36 \%$ manifestaram ter sido sensibilizados e $36 \%$ expressaram ter aprendido muito sobre os problemas ambientais e suas relaçõescom a sociedade atual. Já para $28 \%$ dos participantes, o jogo foi importante para a tomada de atitude com maior responsabilidade individual e coletiva sobre as questões socioambientais. Para uma pequena parcela dos participantes $(1 \%)$, o jogo não teve nenhuma característica capaz de proporcionar uma mudança de comportamento.

Tais resultados nos apontam para o potencial que o Ecoethos da Amazônia possui na sensibilização e capacidade de esclarecer conceitos e situações complexas relacionados aos problemas ambientais e à busca da sustentabilidade. Embora não tão contundente, o jogo é ainda um recurso valioso para o desenvolvimento da responsabilidade e cuidado ambiental. Portanto, ao agrupar a clareza dos problemas ambientais e o estímulo à reflexão sobre estes problemas, observa-se que o jogo apresenta potencialidade para promoção de metas da EA, como sensibilizar/informar e refletir sobre aspectos socioambientais com estes participantes do jogo. Entretanto, aponta-se que estudos complementares são necessários para verificar a efetiva transformação do comportamento e promoção da cidadania ambiental. 


\subsection{A Taxonomia Bloom e o entendimento das temáticas socioambientais}

Considerando que os conteúdos abordados no Ecoethos da Amazônia são diversos e se agrupam a partir dos elementos simbólicos (água, ar, terra e fogo), como esses adolescentes avaliam seu aprendizado?

Na Tabela 2 estão discriminados os graus de concordância relativos à capacidade para a efetiva aprendizagem referente aos itens abordados no jogo. Observa-se que a aprendizagem dos adolescentes, apesar de ter variado entre os itens em cada estação, ocorreu ora mais intensa ora menosintensa. Desta- cam-se percentuais de entendimento mais elevados nos temas relacionados aos elementos Água, Terra e Fogo. A água tem sido um tema bastante presente dentro e fora docontexto escolar, principalmente pelo fato de, na época da pesquisa, ter-se uma crise hídrica bastante severa assolando o sul e sudeste brasileiro e, por outro lado, ser um dos problemas mais frequentes na cidade de Manaus-AM.

A respeito do entendimento sobre a temática da água, é evidente ser a mais trabalhada nas escolas comparativamente à temática de energia e que aqui obteve grau de entendimento relativamente menor. Isso pode estar associado ao fato de no jogo estarem presentes questões que conflitam com o consumo

TABELA 2 - Graus de concordância sobre a aprendizagem dos conteúdos em cada estação.

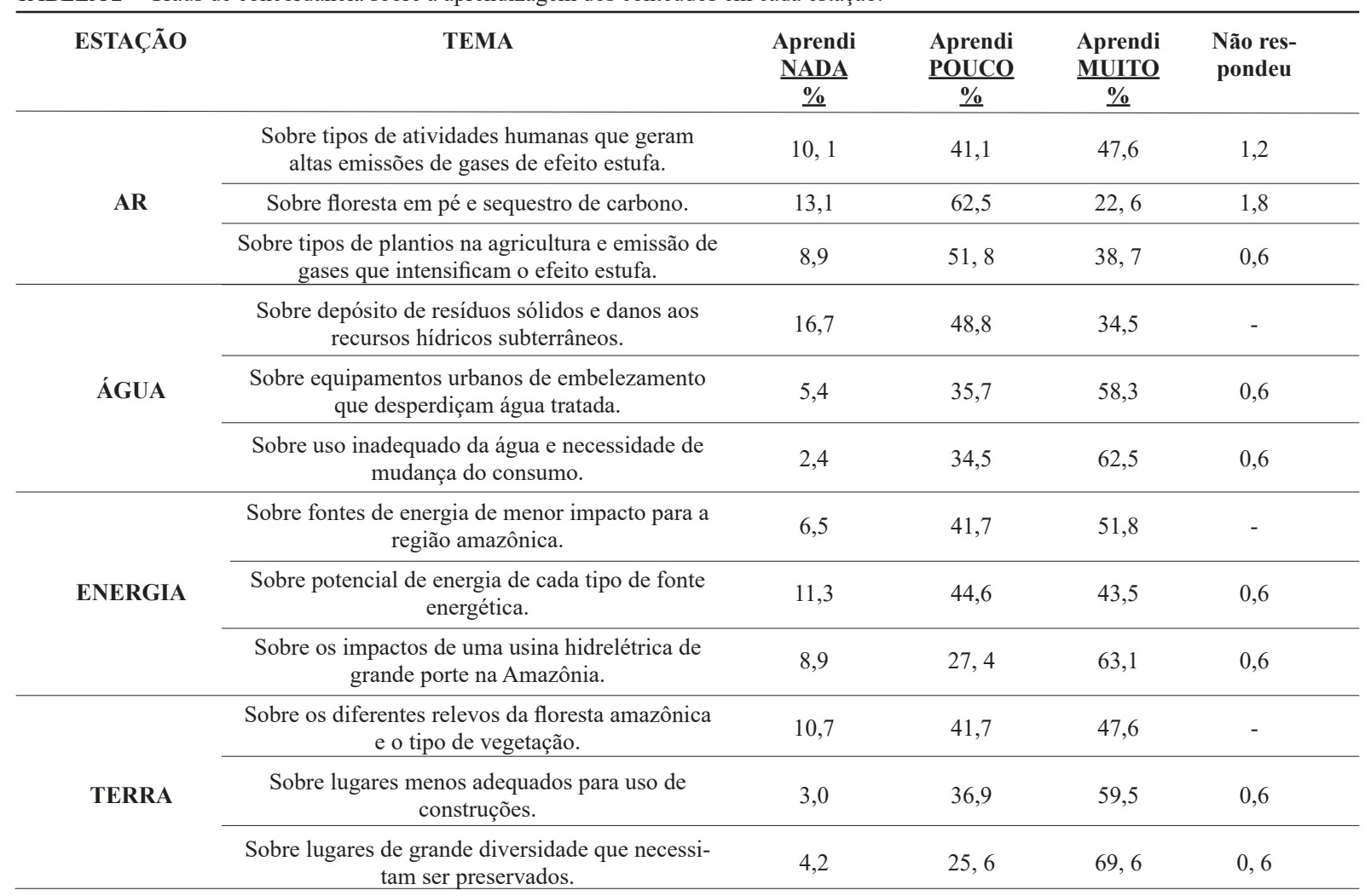


da água, que não é necessariamente o desperdício a partir de práticas de consumo individual, mas a inserção de itens que apreciam aspectos culturais como o uso de equipamentos urbanos de embelezamento de praças (chafarizes). Essa análise mais detalhada será efetuada noutra oportunidade, uma vez que aqui o espaço é exíguo para tal.

Na estação Terra, o tema mais tangível e mais próximo da realidade desses jovens possibilitou o maior índice de entendimento agrupado dos conteúdos. Questões de moradia são elementos importantes para os adolescentes, uma vez que implicam fortemente em sua identidade social e pertencimento (Higuchi, 2003; 2008; Albuquerque \& Higuchi, 2015).

Situação similar para o entendimento dos temas presentes na estação Fogo, a partir da abordagem de fontes energéticas alternativas e menos impactantes ao ambiente amazônico. Na estação $\mathrm{Ar}$, o entendimento nos respectivos temas foi relativamente menor tendo em vista a complexidade do conteúdo, por exemplo, para compreender como uma árvore é capaz de reduzir (absorver) os gases de efeito estufa (gás carbônico) na atmosfera, sendonecessário o processo de fotossíntese. Vários estudos apontam que a complexidade de entendimento da temática que envolve a Mudança Climática favorece uma incerteza sobre o tema e retarda a mudança necessária para um comportamento pró-ambiental (Swim et al., 2009; Lima \& Layrargues, 2014; Sousa et al., 2013).

Ao considerarmos os graus de entendimento dos participantes de forma agrupada sobre cada tema/elemento, a Estação Terra foi onde 59\% dos adolescentes citaram ter aprendido muito.Seguidos pela compreensão dos itens da Estação Fogo/Energia, onde essa aprendizagem ocorreu para 53\%dos participantes. Na Estação Água a aprendizagem foi elevada para $52 \%$ dos participantes. Finalmente, nos itens relativos à Estação Ar, tiveram aprendizagem elevada com apenas $37 \%$ dos participantes. Por sua vez, os entendimentos mais baixos foi exatamente o reverso, ou seja, na Estação Ar (52\%), Água (40\%), Fogo (38\%) e Terra $(34,8 \%)$ e nulo (nenhum entendimento) respectivamente na estação $\operatorname{Ar}(11 \%)$, Fogo (9\%), Água (8\%) e Terra (6\%).

Destaca-se, assim, que o relativo maior entendimento dos participantes referiu-se às problemáticas relacionadasao uso adequado da terra e o relativo menor entendimento foi sobre as emissões de gases de efeito estufa (GEE) desenvolvidona Estação Ar. Isso pode nos indicar a maior complexidade das temáticas relativas ao fenômeno de emissão dos GEEs e o papel da floresta na neutralização do carbono, os quaisnão são conceitos lineares ou absolutos, mas envolvem uma trama complexa de vários aspectos, portanto, exigindo estruturas cognitivas mais elaboradas.

No entanto, apesar da complexidade sobre a estação Ar (especialmente sobre a mudança climática), o jogo permite um avanço significativo para a sua compreensão, que em outros métodos didáticos não se mostra tão expressivo. Portanto, os resultados indicam que de modo geral o jogo proporciona aspectos salientes para a compreensão dos temas abordados.

\section{Considerações finais}

Os resultados apresentados pelos adolescentes participantes nos permitem considerar que o Ecoethos da Amazônia assume um forte caráter educacional ao possibilitar a exploração das múltiplas competências e habilidades dos participantes 
assim como definidas pela TB (Bloom et al., 1988; Krathwohl, 2002; Ferraz \& Belhot, 2010), bem como os aspectos relativos a EU (Bernaupt, 2010; Tullis \& Albert, 2013).

Segundo Silva et al. (2012) a EA lúdica, a partir de temas atuais e reais possibilitam o vivenciar, o experimentar, o explorar, o pensar e o aprender com os erros, com acessoao aprendizado de forma dinâmica, desenvolvendo habilidades e competências interpessoais.

Fica evidente que o jogo possibilitou problematizar a ética que se fundamenta na responsabilidade como aponta Sauvé (2005), a qual consideraser nitidamente mais rica do que a ética da sustentabilidade, que busca atender o desenvolvimento. Portanto, falta trazer para o âmbito escolar a racionalização não somente sobre questões ambientais, mas também a internalização de problemas éticos como a falta de coletividade e corresponsabilidade frente à crise socioambiental para a busca de uma sociedade sustentável. Isso deixa evidente uma caracterização de um recurso paradidático por tratar de questões além do currículo escolar e valores éticos (cooperação).

Com esta reflexão, o Ecoethos da Amazônia mostra-se como potencial recurso para trazer à discussão a trajetória árdua da EA em promover na sociedade o pensamento crítico e reflexivo, como forma de alcançar a meta tão almejada da EA (cidadania ambiental). Higuchi \& Azevedo (2004) apontam a EA como um elemento fundamental na promoção de mudanças de comportamentos visando à formação da cidadania ambiental. Dessa maneira, tais resultados evidenciaram que o caráter simulador, lúdico e cooperativo esteve presente no Ecoethos da Amazônia e pôdepromover as metas cognitivas e afetivas preconizadas pelo processo de EA, segundo os adolescentes participantes.
Esta investigação evidenciou a contribuição do Ecoethos da Amazônia direcionada aos aspectos cognitivos e afetivos no comportamento dos alunos, para o desenvolvimento de um comportamento pró-ambiental. Destaca-se o fato de que seu formato lúdico permitiu aos participantes interagir entre si, sendo o fator que mais os agradou.

Tal resultado evidencia o quanto as relações interativas têm sido substituídas pelas tecnologias, que ao serem mal utilizadas promovem nas relações humanas o que Káplun (1999, p. 71) denomina de "seres tecnologicamente hipercomunicados, mas socialmente isolados". Portanto, o Ecoethos da Amazônia mostrou-se efetivo em reduzir o isolamento social, ao promover a interação entre os participantes durante a atividade. Esse ponto é importante para que seja estabelecido na sociedade um diálogo sobre questões socioambientais e possibilite-se a construção da real cidadania em busca do bem comum.

O envolvimento ativo neste jogo de simulação possibilitou aos alunos enxergar a relação pessoa-ambiente e as consequências futuras sobre as decisões. A EA busca mediante suas metas essa mudança de comportamento, que pôdeser inicialmente percebida pelos participantes durante o jogo. Dessa forma, a aplicação de técnicas de simulação em programas e projetos de EA mostrou-se efetiva no Ecoethos da Amazônia, evidenciando o que Taylor (1991) apontou: que a simulação é especialmente conveniente para a EA.

\section{Agradecimentos}

À Coordenação de Aperfeiçoamento de Pessoal de Nível Superior (CAPES) pelo financiamento da pesquisa, ao Programa de Pós Graduação de 
Ciências do Ambiente e Sustentabilidade na Amazônia, ao Laboratório de Psicologia e Educação Ambiental (LAPSEA) do Instituto Nacional de Pesquisas da Amazônia (INPA), aos gestores, professores e alunos das escolas participantes.

\section{Referências}

Albuquerque, D. S; Higuchi, M. I. G. Implicações socioafetivas do jovem com o local de moradia. In: Machado, F. V. ; Massola, G. M.; Ribeiro, A. T. (Org.). Estado, Ambiente e Movimentos Sociais, 8, 264-283, 2015. Florianópolis, SC: Edições do Bosque. 2015. Disponível em: https://repositorio.ufsc.br/xmlui/handle/123456789/135471

Alves, L.; Hetkowski, T. M. Espaços Vividos e Jogos Digitais: ambientes propícios para produção de novas formas de letramentos e de conteúdos interativos pela geração C. In: Pesce, L.; Oliveira, M. O. M. (Org.). Educação e Cultura Midiática, 2, 65-88, 2012. Disponível em: https://portal. uneb.br/eduneb/wp-content/uploads/sites/73/2017/05/ Educacao_e_Cultura_Midiatica_Volume_II.pdf

Aragonés, J. I.; Amérigo, M. Psicología Ambiental: Aspetos conceptuales y metodológicos. In: Aragones, J. I.; Amérigo, M. (Eds.). Psicológía Ambiental. 3o. ed. Madrid.: Ediciones Pirámide., 2002. v. 1 p. 23-42.

Azevedo, G. C. Ecoethos da Amazônia: Problemática socioambientais para um pensar e agir responsável. Mimeo. Manaus: 2014.

Azevedo, G. C.; Higuchi, M. I. G. Entendimento juvenil dos quatro elementos naturais: contribuição para a conservação da floresta amazônica. In: Anais do VII Seminário Brasileiros sobre Áreas Protegidas e Inclusão Social e II Encontro Latino Americano sobre Áreas Protegidas e Inclusão Social. Culturas e Biodiversidade: o presente que temos e o futuro que queremos. Florianópolis, 28 de out., 2015. p. 815-825. Disponível em: .http://sapiselapis2015. paginas.ufsc.br/anais. Acesso em: jan. 2016.

Azevedo, G. C.; Higuchi, M. I. G.; Barcelos, V. Contribuição do INPA na formação continuada de professores em educa- ção ambiental: desafios, práticas e reflexões. Ambiente \& Educação, 14, 89-110, 2009.

Balasubramanian, N.; Wilson, B. G. Games and simulations. In: Society for Information Technology and Teacher Education International Conference, 1, 1-8, 2005. Disponível em: http://site.aace.org/pubs/foresite/GamesAndSimulations1. pdf. Acesso em: ago. 2019

Bernhaupt, R. User eXperience evaluation in entertainent. In: Bernhaupt, R. (Org.). Evaluating User eXperience in Games: Concepts and Methods. France: Springer, p. 3-10, 2010. doi: 10.1007/978-1-84882-963-3_1

Bloom, B. S.; Krathwohl, D. R.; Masia, B. B. Taxonomia de objetivos educacionais: domínio afetivo. Porto Alegre: Globo, 1973.

Bloom, B. S.; Engelhart, M. D.; Furst, E. J.; Hill, W. H.; Krathwohl, D. R. Taxonomia de objetivos educacionais. v.1. ed. Rio de Janeiro: Globo, 1988.

Castro, R. Educación ambiental. In: Aragonés, J. I.; Amérigo, M. (Org.). Psicología Ambiental. 3º. ed. Madrid.: Ediciones Pirámide, 1, 357-359, 2002.

Corral-Verdugo, V.; Pinheiro, J. Q. Aproximaciones al estudio de la conducta sustentable. Medio Ambiente y Comportamiento Humano. Editorial Resma, 1-26, 2004. Disponível em: https://mach.webs.ull.es/PDFS/Vol5_1y2/ VOL_5_1y2_a.pdf. Acesso em: ago. 2014.

Ferraz, A. P. C. M.; Belhot, R. V. Taxonomia de Bloom: revisão teórica e apresentação das adequações do instrumento para definição de objetivos educacionais. Gestão \& Produção, 17(2), 421-431. 2010. Disponível em: http:// www.scielo.br/pdf/gp/v17n2/a15v17n2.pdf

Günther, H.; Elali, G. A.; Pinheiro, J. Q. A abordagem multimétodos em estudos pessoa-ambiente: características, definições e implicações. In: Pinheiro, J. Q.; Günther, H. (Orgs.). Métodos de pesquisa nos estudos pessoa-ambiente. São Paulo: Casa do Psicólogo.p. 369-396, 2008.

Higuchi, M. I. G. Making Sense of dwelling place: a study among urban Amazonian children. In: Medio Ambiente y Comportamento Humano: An International EnvironmentalPsychologyReview. Espanha. 9 (1-2), 149-170, 2008. Disponível em: https://mach.webs.ull.es/PDFS/Vol9_1y2/ 
Vol9_1y2_h.pdf. Acesso em: jul. 2016.

Higuchi, M. I. G. Ecoethos da Amazônia: Educação ambiental para juventude na construção da ética do cuidado e responsabilidade para com a floresta amazônica. Manaus: INPA, 2013.

Higuchi, M. I. G.; Azevedo, G. sC. (Org.). Ecoethos da Amazônia: problemáticas socioambientais para um pensar e agir responsável. Manaus. Editora INPA, 2014.

Higuchi, M. I. G. A socialidade da estrutura espacial da casa: processo histórico de diferenciação social por meio e através da habitação. Revista de Ciências Humanas, 33, 49-70, 2003. Disponível em: https://periodicos.ufsc.br/ index.php/revistacfh/article/view/25365

Higuchi, M. I. G.; Azevedo, G. C. Educação como processo na construção da cidadania ambiental. Revista Brasileira em Educação Ambiental (REVBEA)/MMA, 1, 63-70, 2004.

Higuchi, M. I. G.; Farias, M. S. M.; Vieira, F. B. Jogos interativos e dinâmicas de grupo em educação ambiental: temas amazônicos. Manaus: Inpa.2010.

Higuchi, M. I. G.; Kuhnen, A. Percepção e Representação Ambiental: Métodos e Técnicas de Investigação para a Educação Ambiental. In: Pinheiro, J. Q.; Günther, H. (Orgs.). Percepção e representação ambiental: métodos e técnicas de investigação para a educação ambiental. Ed. ${ }^{\circ}$. Casa do psicólogo, p. 181-215, 2008.

Higuchi, M. I. G.; Farias, M. S. M. Pequenos Guias do Bosque da Ciência: trajetória de uma experiência de educação ambiental com crianças na Amazônia. Manaus: INPA, 2002.

Higuchi, M. I. G.; Freitas, C. C.; Vieira, F. B.; Weigel, P.; Farias, M. S. M. Jogo Quebra-charada da Reserva Ducke: Guia didático. Manaus: INPA/Petrobras Ambiental, 2012.

Higuchi, M. I. G.; Vieira, F. B.; Weigel, P.; Farias, M. S. M.; Freitas, C. C.; Assis, L. X.; Oliveira, H. V.; Viana, T. S. R. Jovens Ambientalistas. Projeto Educke: Educação Ambiental para crianças e jovens: um olhar para a Reserva Florestal Ducke. Relatório Técnico. Manaus: INPA/Petrobras Ambiental, 2011.

Higuchi, M. I. G.; Zattoni, M.; Bueno, F. P. Educação Ambiental em contextos não escolares: definindo, problematizando e exemplificando. Pesquisa em Educação Ambiental,
2,119-131, 2012.

Jacobi, P. Educação Ambiental, cidadania e sustentabilidade. Caderno de Pesquisa, 118, 189-205, 2003. doi: 10.1590/ S0100-15742003000100008

Jacobi, P. Educação e meio ambiente - transformando as práticas. Revista Brasileira em Educação Ambiental (REVBEA), 1, 28-35, 2004.

Káplun, M. Processos educativos e canais de comunicação. Comunicação \& Educação, 141, 68-75, 1999. Disponível em: http://www.revistas.usp.br/comueduc/article/ view/36846

Krathwohl, D. R. A revion of Bloom's Taxonomy: An overview. Theory into practice, 41(4), 212-264, 2002. doi: 10.1207/s15430421tip4104_2

Lee, J. J.; Hammer, J. Gamification in Education: What, How, Why Bother? Academic Exchange Quarterly, 15(2), $1-5,2011$.

Lima, G. F. C.; Layrargues, P. P. Mudanças climáticas, educação e meio ambiente: para além do Conservadorismo Dinâmico. Educar em Revista, Edição Especial, 3, 73-88, 2014. Disponível em: http://www.scielo.br/pdf/er/nspe3/ a06nspe3.pdf

Loureiro, F. B. Educação Ambiental Transformadora. In: Layrargues, P. P. (Org.). Identidades da educação ambiental brasileira. Brasília: Ministério do Meio Ambiente, p. 65- 84,2004.

Mattos, R. A. L.; Fagundes, T. C. P. C. A importância dos jogos para a construção de conceitos matemáticos. In: Tenório, R. M.; Silva, R. S. (Orgs.). Capacitação docente e responsabilidade social: aportes pluridisciplinares. Salvador: EDUFBA, p. 77-96, 2010. Disponível em: http:// books.scielo.org/id/329/05

Petry, A. S.; Battaiola, A. L.; Bahia, A. B.; Petry, L. C.; Clua, L. R. M; Vargas, A. Parâmetros, estratégias e técnicas de análise de jogo: o caso A mansão de Quelícera. In: XII Simpósio Brasileiro de Games. São Paulo, p. 141-151, 2013. Disponível em: <http://www.sbgames.org/sbgames2013/ proceedings/cultura/Culture-19_full.pdf.> Acesso em: jun. 2016

Rodrigues, P.; Nunes, A. L. Revista da Abordagem Gestál- 
tica, 2, 2010. Disponível em: http://pepsic.bvsalud.org/pdf/ rag/v16n2/v16n2a09.pdf

Sato, M. Educação Ambiental. Ryma: São Carlos, 2002.

Santos, E. C. Educação Ambiental e a tranversalidade na formação de professores: complexidade e desafios do mundo contemporâneo. Revista Geonorte, 3(4), 161-170, 2012. Disponível em: http://www.periodicos.ufam.edu.br/ revista-geonorte/article/view/1932/1807

Sauvé, L. Educação Ambiental: possibilidades e limitações. Université du Québec à Montréal. Educação e Pesquisa, 31(2), 317-322, 2005. Disponível em: http://www.scielo. br/pdf/ep/v31n2/a12v31n2.pdf

Savi, R.; Von Wangenheim, C. G.; Ulbricht, V.; Vanzint, T. Proposta de um modelo de avaliação de Jogos Educacionais. Novas tecnologias em educação, 8,1-12, 2010. Disponível em: http://seer.ufrgs.br/index.php/renote/article/ view/18043/10630

Schwartz, G. Brinco, logo aprendo: educação, videogames e moralidades pós-modernas. São Paulo: Paulus, 2014.

Silva, F. W.; Sammarco, Y. M.; Teixeira, A. F. Educação ambiental lúdica: diálogos dos corpo, lazer e arte. In: Lisboa, C. P.; Kindel, E. A. I. (Orgs.). Educação ambiental: da teoria à prática. Porto Alegre: Mediação, p. 49 - 69, 2012.

Smyth, J. C. Environment and Education: a view of a changing scene. Environmental Education Research, 1(1), 3-120, 1995. doi: 10.1080/1350462950010101
Sousa, A. W. F.; Higuchi, M. I. G.; Azevedo, G. C. Percepções sobre o papel da floresta nas mudanças climáticas: um estudo com alunos do ensino médio em Manaus-AM. In: Anais do II Congresso de Iniciação Científica PIBIC/ $C N P q$ - PAIC/FAPEAM. Manaus, 24 de jun., 2013. p.1-4.

Swim, J.; Clayton, S.; Doherty, T.; Gifford, R.; Howard, G.; Reser, J.; Stern, P.; Weber, E. Psychology \& Global Climate Change: addressing multifaceted phenomenon and setof challenges. 108p. 2009. Disponível em: $<$ https://www. apa.org/science/about/publications/climate-change-booklet. pdf $>$ Acesso em: jul. 2016.

Taylor, J. L. Guia sobre simulacion y juegos para la Educacion Ambiental. Santiago, Chile, 1991. Disponível em: $<$ https://unesdoc.unesco.org/ark:/48223/pf0000056905_spa $>$ Acesso em: ago. 2019

Tullis, T.; Albert, B. Measuring the User eXperience: Collecting, Analyzing, and Presenting. In: Tullis, T.; Albert, B. (Orgs.). USA: Elsevier. 1- 14, 2013. doi: 10.1016/B978-012-415781-1.00001-7

Unesco. Conferencia Intergubernamental sobre Educación Ambiental. v. 1, p. 97, 1978. Disponível em: <http://unesdoc. unesco.org/images/0003/000327/032763sb.pdf $>$ Acesso em: set. 2014. 